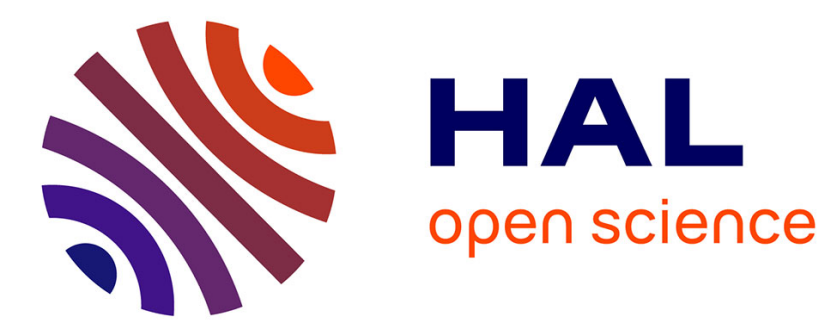

\title{
rf linewidth reduction in a quantum dot passively mode-locked laser subject to external optical feedback
}

C.-Y. Lin, Frédéric Grillot, N. A. Naderi, Y. Li, L. F. Lester

\section{To cite this version:}

C.-Y. Lin, Frédéric Grillot, N. A. Naderi, Y. Li, L. F. Lester. rf linewidth reduction in a quantum dot passively mode-locked laser subject to external optical feedback. Applied Physics Letters, 2010, 96 (5), pp.051118. 10.1063/1.3299714 . hal-00501875

\section{HAL Id: hal-00501875 \\ https://hal.science/hal-00501875}

Submitted on 16 Nov 2010

HAL is a multi-disciplinary open access archive for the deposit and dissemination of scientific research documents, whether they are published or not. The documents may come from teaching and research institutions in France or abroad, or from public or private research centers.
L'archive ouverte pluridisciplinaire HAL, est destinée au dépôt et à la diffusion de documents scientifiques de niveau recherche, publiés ou non, émanant des établissements d'enseignement et de recherche français ou étrangers, des laboratoires publics ou privés. 


\title{
RF linewidth reduction in a quantum dot passively mode-locked
}

\section{laser subject to external optical feedback}

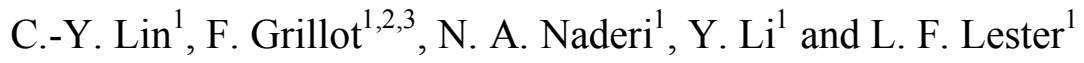 \\ ${ }^{1}$ Center for High Technology Materials, The University of New Mexico \\ 1313 Goddard SE, Albuquerque, NM 87106, USA \\ ${ }^{2}$ CNRS FOTON-INSA, 20, avenue des buttes de Coesmes, 35043 Rennes Cedex , France \\ ${ }^{3}$ CNRS FOTON-ENSSAT, 6 Route de Kerampont, 22305 Lannion Cedex , France
}

\begin{abstract}
The effect of external optical feedback on an InAs/GaAs quantum dot passively mode-locked laser is investigated. The RF linewidth narrows from $8 \mathrm{KHz}$ in the free-running situation to a value as low as $350 \mathrm{~Hz}$ under relatively low feedback. The RF linewidth characterization under resonant feedback at a multiple of the laser cavity length validates the prediction of a previous numerical simulation. It is also confirmed that the integrated rms timing jitter varies as the square root of the RF linewidth. The results are promising for the development of compact, monolithic semiconductor mode-locked lasers as low noise optoelectronic oscillators.
\end{abstract}

Corresponding Author: Chang-Yi Lin (cylin@unm.edu) 
Monolithic mode-locked lasers (MLLs) are promising candidates for inter-chip/intra-chip clock distribution as well as high bit-rate optical time division multiplexing, arbitrary waveform generation and microwave signal generation due to their compact size, low power consumption, and direct electrical pumping. ${ }^{1,2}$ Several unique characteristics of quantum dot (QD) materials, such as ultra broad bandwidth, ultra fast gain dynamics, and easily saturated gain and absorption, make them an ideal choice for semiconductor monolithic MLLs. ${ }^{3-5}$ The RF linewidth, which directly influences the phase noise spectral density, is directly related to the integrated rms timing jitter in a semiconductor passive MLL. ${ }^{6}$ Thanks to the lower threshold current density and the lower associated spontaneous emission noise in QD laser devices compared to their quantum well (QW) counterparts, the RF linewidth is generally narrower in a passive QDMLL. In a large number of these applications, performance of the laser in an external optical cavity is an important feature, as the laser is likely to be monolithically integrated on chip with other devices, in which case optical isolation is difficult. In various practical situations, MLLs may be subjected to optical feedback generated by discrete reflections. These perturbations may be induced by discontinuities in the optical waveguide of the monolithic chip or at the device-package interfaces from other optical devices placed along an optical fiber. A number of experimental studies have been performed so as to evaluate the sensitivity of Quantum Well (QW) based MLLs under optical feedback. ${ }^{7,8}$ In our previous study ${ }^{9}$, the feedback resistance in a passive QDMLL was first analyzed in an arbitrary feedback loop (non-resonant case). Beyond a certain feedback level, the effect of external feedback was found to be detrimental for mode-locking operation enhancing noise in the RF electrical signal. According to the numerical investigation from Avrutin et al. ${ }^{10}$, however, the timing stability of a two-section passive QDMLL can be 
improved by introducing a controlled external feedback loop (resonant case) to reduce the phase noise.

In this paper, we experimentally investigate the effect of external optical feedback on a monolithic two-section passive QDMLL operating at a $5.1 \mathrm{GHz}$ repetition rate. When the external cavity length is tuned to the resonant case, ${ }^{10}$ at relatively moderate feedback strength, $-36 \mathrm{~dB}$, the RF linewidth is reduced from $8 \mathrm{KHz}$ in the free-running condition to a very low value of $350 \mathrm{~Hz} .{ }^{11}$ The effects of optical feedback vary periodically as the length of feedback loop is changed, with a period equal to the mode-locking frequency of the laser device.

The laser epitaxial structure of the MLL device is a multi-stack "Dots-in-a-WELL" (DWELL) structure that is composed of an optimized six-stack InAs QD active region grown by elemental source molecular beam epitaxy $(\mathrm{MBE})$ on an $\mathrm{n}+$-doped, $<100>$-oriented GaAs substrate. ${ }^{12}$ The $3-\mu \mathrm{m}$-wide optical ridge-waveguide devices are fabricated following standard dry-etch, planarization, and metallization processing. The two-section QD passive MLLs are made with a total cavity length of $7.8-\mathrm{mm}$ and a saturable absorber (SA) length of $1.1-\mathrm{mm}$. A highly reflective coating $(\mathrm{R} \approx 95 \%)$ is applied to the mirror facet next to the SA and the output facet is cleaved $(\mathrm{R} \approx 32 \%)$.

The QDMLL device was investigated under external optical feedback using the experimental setup similar to our previous report. ${ }^{9}$ However, an optical delay line that has a stepcontrolled fine delay stage was also introduced to change the external fiber loop length as shown in Fig. 1. Injected feedback into the laser is defined as the ratio $\Gamma=P_{1} / P_{0}$ where $P_{1}$ is the power returned to the facet and $P_{0}$ the emitted one. The optical coupling loss of the device to the fiber was estimated to be about $-5 \mathrm{~dB}$ and kept constant during the whole experiment. 
All measurements were operated at a controlled substrate temperature of $20^{\circ} \mathrm{C}$. Fig. 2 shows the ex-fiber light-current (LI) curve of the laser under various absorber biases. The inset is the optical spectrum showing the peak lasing wavelength at $1.33-\mu \mathrm{m}$. Fig. 3 shows the RF spectrum results with and without (free-running) external feedback under 280-mA DC bias on the gain section and $-1 \mathrm{~V}$ applied to the absorber. By optimizing the fiber loop length through the optical delay line to the integer resonant case, the 3-dB RF linewidth was improved from $8 \mathrm{KHz}$ to 350 Hz. This situation is obtained when the optical length of the external cavity $L_{e x t}$ is a multiple of that of the solitary laser $L$ such as $L_{e x t} L \approx n=1,2,3, \ldots$ Under the resonant condition, stabilization of the laser can be obtained. ${ }^{10}$ The minimum RF linewidth under external feedback shown in the inset of Fig. 4 was confirmed with a Lorentzian curve-fitting of the electrical spectrum analyzer (ESA) data using a frequency span of $250 \mathrm{KHz}$ and a resolution bandwidth of $300 \mathrm{~Hz}$. This measured linewidth reduction should lower the phase noise and enable a decrease of the integrated rms timing jitter by a factor of $\sim 4.8 .^{6}$ According to the analytical expression from Kefelian et al. $^{6}$, the integrated ms timing jitter is proportional to the square root of the RF linewidth. Fig. 5 experimentally validates this jitter-linewidth relation in the free-running case under the conditions of a fixed absorber voltage of $-0.5 \mathrm{~V}$ and the integration of the singlesideband phase noise (SSB-PN) spectral density, $\mathrm{L}(f)$, at the fourth harmonic over the offset frequency range of $30 \mathrm{KHz}$ to $30 \mathrm{MHz} .^{13}$

The variation of the RF linewidth as a function of the optical feedback ratio for the integer resonant case at a gain current of $280 \mathrm{~mA}$ and a reverse voltage of $-1 \mathrm{~V}$ is shown in Fig. 4. The $\mathrm{RF}$ linewidth was reduced to under $800 \mathrm{~Hz}$ at a low feedback ratio $(\sim-57 \mathrm{~dB})$ and maintained at or below this level with increasing feedback ratio. It did not display the broadening effect 
compared to the free-running condition at low feedback ratio that was reported in ref. 14 . The minimum RF linewidth, $350 \mathrm{~Hz}$, was observed at a relatively moderate feedback strength of about $-36 \mathrm{~dB}$. In contrast, Merghem et al. ${ }^{11}$ reported that a significantly stronger feedback level ($22 \mathrm{~dB}$ ) was needed to reduce the RF linewidth to its lowest value in a pulsed QDash laser at $1550 \mathrm{~nm}$. This difference of roughly $14 \mathrm{~dB}$ is attributed to the lower threshold current density generally encountered in $1310 \mathrm{~nm}$ quantum dot lasers on a GaAs substrate compared to QDash materials technology, which leads to a smaller free-running RF linewidth in the device.

We have also explored the variation in center frequency and RF linewidth as the feedback loop is changed through the optical delay line (Fig. 6). The experimental results demonstrate a similar trend to those observed in QWMLLs under optical external feedback ${ }^{7}$ and confirm the numerical simulation result from Avrutin et $\mathrm{al}^{10}$ in a two-section monolithic MLL under the integer resonant feedback case. The periodicity can be viewed approximately as $1.5-\mathrm{mm}$ (delay time: $\sim 200 \mathrm{ps}$ ), which corresponds to the mode-locking frequency of $\sim 5 \mathrm{GHz}$. It is noted that when approaching the exact resonant condition $\left(\mathrm{L}_{\text {ext }}=\mathrm{nL}\right)$, the noise is enhanced and the laser can become unstable with stronger optical feedback. For instance, an increase in the RF linewidth, which is a sign of the noise in the laser cavity, is observed in Fig. 6. This experimental result corroborates the numerical simulation result for an integer resonant case in which it was shown that the laser under near-exactly resonant feedback could follow very specific nonlinear dynamics. ${ }^{10}$

In summary, we have investigated experimentally the stabilizing effect of external optical feedback on a two-section passive InAs/GaAs QDMLL and demonstrated that the experimental results agree well with previously published theory. The RF linewidth was reduced to a very 
small value of $350 \mathrm{~Hz}$ considering any semiconductor two-section passive MLL reported up-todate. The narrow linewidth with external optical feedback offers an attractive method for highspeed and low-jitter chip-to-chip optical interconnects.

\section{Acknowledgments}

This work was supported by the Air Force Office of Scientific Research under Grant Nos. FA9550-06-1-0411 and FA9550-09-1-0490. 


\section{References}

${ }^{1}$ G. A. Keeler, B. E. Nelson, D. Agarwal, C. Debaes, N. C. Helman, A. Bhatnagar, and D. A. B. Miller, IEEE J. Sel. Top. Quantum Electron. 9, 477 (2003).

${ }^{2}$ C.-Y. Lin, Y.-C. Xin, J. H. Kim, C. G. Christodoulou, and L. F. Lester, IEEE Photonics Journal 1, 236 (2009).

${ }^{3}$ E. U. Rafailov, M. A. Cataluna, W. Sibbett, Nature Photonics 1, 395 (2007).

${ }^{4}$ F. Lelarge, B. Dagens, J. Renaudier, R. Brenot, A. Accard, F. Van Dijk, D. Make, O. LeGouezigou, J. G. Provost, F. Poingt, J. Landreau, O. Drisse, E. Derouin, B. Rousseau, F.

Pommereau, and G. H. Duan, IEEE J. Sel. Top. Quantum Electron. 13, 111 (2007).

${ }^{5}$ C.-Y. Lin, Y.-C. Xin, Y. Li, F. L. Chiragh, and L. F. Lester, Opt. Express 17, 19739 (2009).

${ }^{6}$ F. Kefelian, S. O'Donoghue, M. T. Todaro, J. G. McInerney, G. Huyet, IEEE Photon. Technol. Lett. 20, 1405 (2008).

${ }^{7}$ O. Solgaard and K. Y. Lau, IEEE Photon. Technol. Lett. 5, 1264 (1993).

${ }^{8}$ M. Passerini, G. Giuliani and M. Sorel, IEEE Photon. Technol. Lett. 17, 965 (2005).

${ }^{9}$ F. Grillot, C.-Y. Lin, N. A. Naderi, M. Pochet, and L. F. Lester, Appl. Phys. Lett. 94, 153503 (2009).

${ }^{10}$ E. A. Avrutin and B. M. Russell, IEEE J. Quantum Electron. 45, 1456 (2009).

${ }^{11}$ K. Merghem, R. Rosales, S. Azouigui, A. Akrout, A. Martinez, F. Lelarge, G.-H. Duan, G. Aubin, and A. Ramdane, Appl. Phys. Lett. 95, 131111 (2009). 
${ }^{12}$ Y.-C. Xin, Y. Li, A. Martinez, T. J. Rotter, H. Su, L. Zhang, A. L. Gray, S. Luong, K. Sun, Z. Zou, J. Zilko, P. M. Varangis, and L. F. Lester, IEEE J. Quantum Electron. 42, 725, (2006).

${ }^{13}$ M. J. W. Rodwell, D. M.Bloom, and K. J. Weingarten, "Subpicosecond laser timing stabilization,” IEEE J. Quantum Electron. 25, 817 (1989).

${ }^{14}$ K. Merghem, S. Azouigui, A. Akrout, A. Martinez, F. Lelarge, A. Shen, G.-H. Duan, G. Aubin, and A. Ramdane, Conference on Lasers and Electro-Optics (CLEO), CTuQ3 (2009). 


\section{Figure Captions:}

Figure 1: Schematic drawing of the experimental setup.

Figure 2: Light current characteristics measured at $20^{\circ} \mathrm{C}$ under various absorber biases. The figure in inset shows the optical spectrum under 280-mA gain current and -1 V reverse voltage.

Figure 3: Comparison of RF spectra with (red) and without (blue) feedback.

Figure 4: RF linewidth as a function of external feedback ratio at a bias of 280-mA gain current and $-1 \mathrm{~V}$ on the absorber. Inset: RF linewidth of $350 \mathrm{~Hz}$ under a feedback ratio of $-36 \mathrm{~dB}$

Figure 5: Integrated timing jitter as a function of the RF linewidth under a bias condition of -0.5 $\mathrm{V}$ reverse voltage and various gain currents in the free-running case. Inset: SSB-PN spectral density $\mathrm{L}(f)$ of the fourth harmonic under 300-mA gain current and $-0.5 \mathrm{~V}$ reverse voltage.

Figure 6: Center frequency shift and RF linewidth varition under feedback ratio of $-30 \mathrm{~dB}$ as a function of optical delay line change, showing a periodicity of roughly $1.5-\mathrm{mm}$ corresponding to the laser round trip time of 200 ps. Bias condition of MLL: 280-mA gain current and $-1 \mathrm{~V}$ reverse voltage. 
Figure 1.

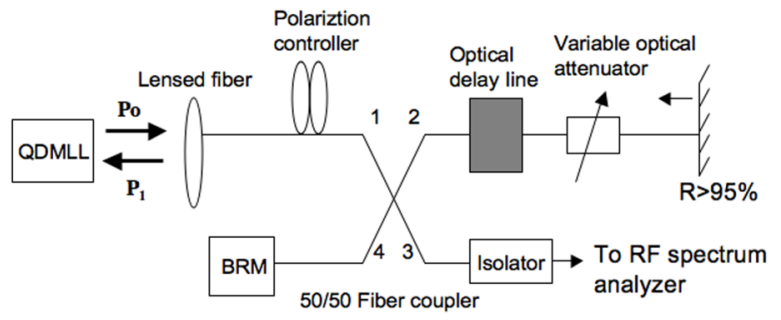


Figure 2.

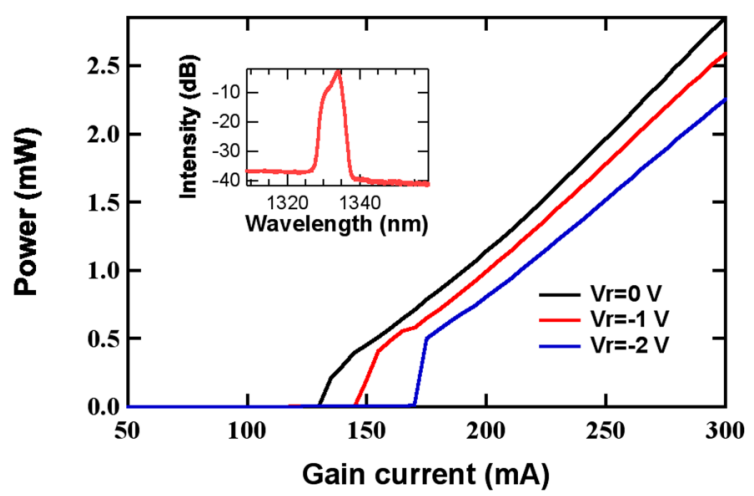


Figure 3.

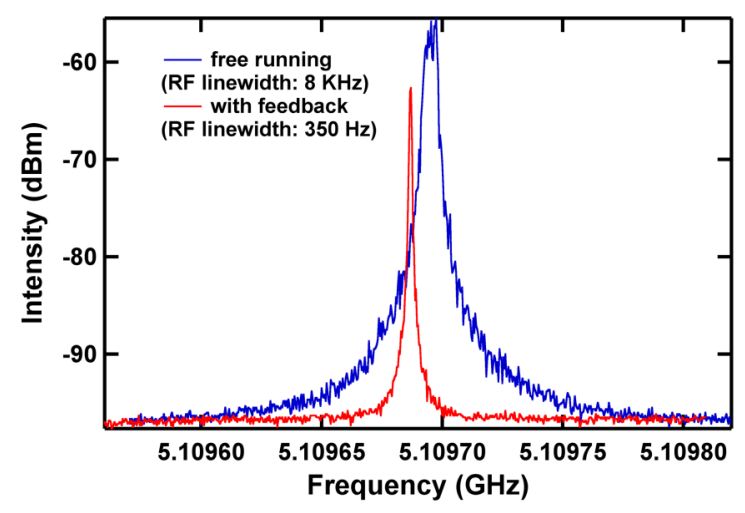


Figure 4.

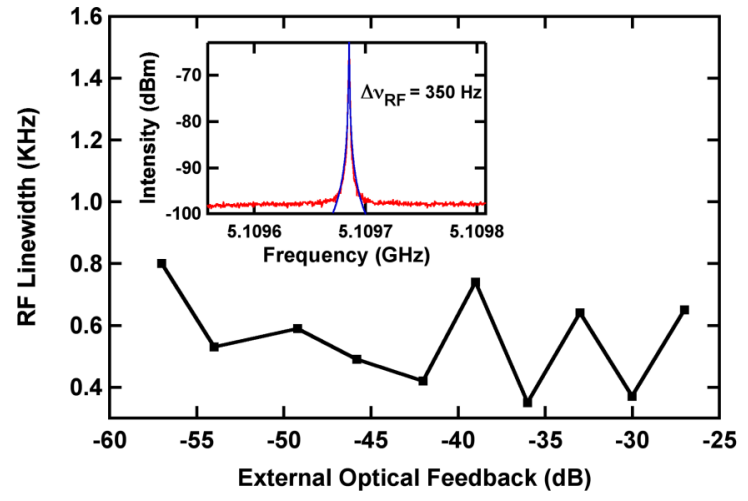


Figure 5.

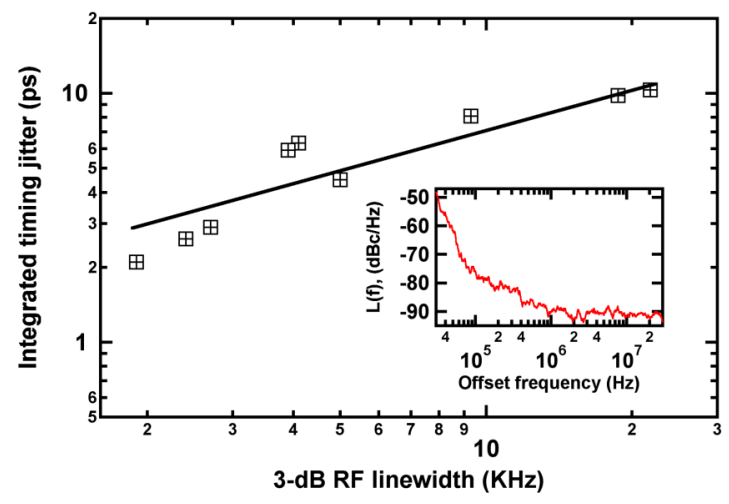


Figure 6.

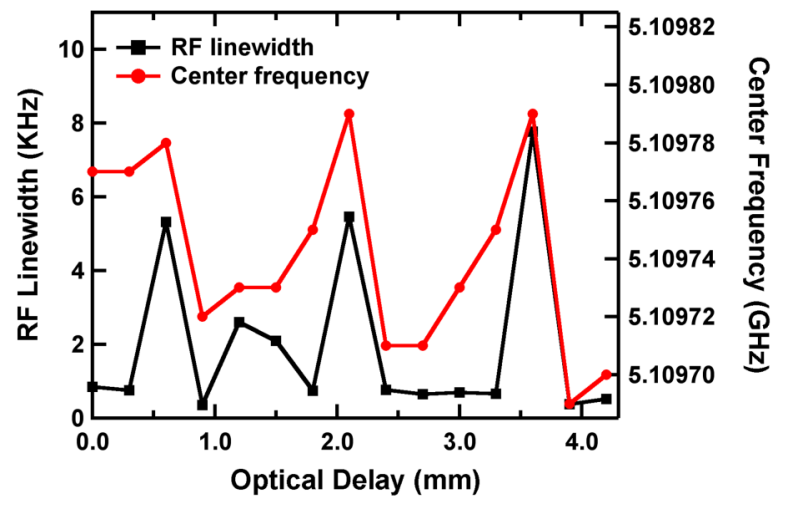

